\title{
BMJ Open How does the outcome of research training fellowships funded via the NHS compare with that from competitively funded fellowships from the MRC and other charities: a cross- sectional retrospective survey of trainees undertaking research training in the West Midlands
}

\author{
Charlotte Maybury, ${ }^{1,2}$ Matthew David Morgan, ${ }^{1}$ Russell Smith, ${ }^{2}$ Lorraine Harper ${ }^{1,2}$
}

To cite: Maybury C,

Morgan MD, Smith R, et al. How does the outcome of research training fellowships funded via the NHS compare with that from competitively funded fellowships from the MRC and other charities: a cross-sectional retrospective survey of trainees undertaking research training in the West Midlands. BMJ Open 2018;8:e019630. doi:10.1136/ bmjopen-2017-019630

- Prepublication history and additional material for this paper are available online. To view these files, please visit the journal online (http://dx.doi. org/10.1136/bmjopen-2017019630).

Received 14 September 2017 Revised 8 December 2017 Accepted 11 December 2017

Check for updates

${ }^{1}$ Institute of Clinical Sciences, College of Medical and Dental Sciences, University of Birmingham, Birmingham, UK ${ }^{2}$ Health Education England (West Midlands), Birmingham, UK

Correspondence to Professor Lorraine Harper; I.harper@bham.ac.uk

\section{ABSTRACT}

Objectives This study aimed to investigate the impact of research training funded via the National Health Service (NHS) on medical trainees compared with traditional clinical research training fellowships (CRTFs).

Design, setting and participants Online survey of 221 clinical trainees who had completed a period of research during their clinical training between 2009 and 2015 in the West Midlands.

Main outcome measures Research outcomes. Results Overall response rate was $59 \%$, of whom 72 participants were funded by CRTFs and 51 funded by the NHS. Although participants with CRTFs were more likely to be awarded a higher degree compared with those on NHS-administered funding (66/72 CRTFs and $37 / 51$ NHS, $P=0.005$ ), similar proportions of NHS-funded and CRTF-funded participants entered clinical lecturer posts on completing initial research training $(8 / 51 \mathrm{NHS}$ and $16 / 72 \mathrm{CRTF}, \mathrm{P}=0.37) .77 \%$ of participants had three or more publications (CRTF 57 and NHS 39,P=0.72). 57 participants had completed clinical training; similar proportions of CRTF-funded and NHS-funded trainees had research included in their consultant contract (12/22 NHS and $14 / 26$ CRTF, $P=0.96$ ) or were appointed to academic posts ( 3 of 25 NHS funded and 6 of 32 CRTF, P>0.05). 95\% of participants would recommend to colleagues and $82 \%$ of participants felt the research experience improved their provision of clinical care with no difference between CRTFfunded and NHS-funded participants $(P=0.49)$. Continuing to participate in clinical work during the research reduced reports of trainee difficulty on returning to clinical work (23/108 continued clinical work vs $12 / 22$ no clinical work, $\mathrm{P}=0.001$ ).

Conclusion Research training funded by the NHS provides a quality experience and contributes to the clinical academic capacity within the UK. More needs to be done to support NHS participants to successfully achieve a higher degree.
Strengths and limitations of this study

- The study systematically identified all clinical trainees from the West Midlands undertaking research using a prospectively collected database.

- The study uses conferment of degree, progression to further academic appointments, number of publications and participants' perception of impact on clinical care as measures of success.

- The study uses a retrospective questionnaire based design.

- The study defines as National Health Service (NHS) funding all sources of research training funding, other than self-funding and clinical research training fellowships (CRTFs) when trainees self-identified as funded by the NHS. The study is unable to identify these sources of funding in more detail. Trainees in receipt of CRTFs were asked to identify whether their funding was from Medical Research Council, Cancer Research UK, National Institute of Health Research, Wellcome Trust or other charities.

- Due to the characteristics of medical trainees in the West Midlands the study may not be widely generalisable.

\section{INTRODUCTION}

Effective translation of scientific discoveries into clinical practice has a major impact on improving medical care. By bringing a clinical perspective, academic clinicians are ideally placed to identify a need for more scientific evidence in patient care and to incite new scientific questions. Clinical academics play a significant role in medical research, especially in shortening the 
time to translation between basic research and clinical practice. ${ }^{12}$ In order to follow a clinical academic career path, junior doctors (trainees) are required to undertake a period of dedicated biomedical research training with the aim of attaining a higher degree, such as a PhD or MD. Funding is available from a variety of different sources. Organisations such as the Medical Research Council (MRC), National Institute of Health Research (NIHR) and medical charities fund clinical research training fellowships (CRTFs) of 2-3 years duration. Approximately, 350 of these CRTFs are awarded per year through open competition. ${ }^{3}$ CRTFs provide excellence in research training and successfully obtaining a competitive CRTF is predictive of progression to a clinical academic leadership role ${ }^{3-5}$ although a recent review reported that only one-third of people completing a CRTF progress to more senior academic posts. ${ }^{5}$

Research fellow training is also funded by alternative sources in the UK which are administrated through the National Health Service (NHS). The money to fund these fellows is often provided from local hospital charitable funds and locally held research funds provided by industry to individual consultants, fellows are then employed via the NHS. The process for a trainee to secure these fellowships differs from that undertaken for CRTFs; the funding decision is generally made at a local level within the NHS, the research project may be funded without undergoing robust peer review and appointment is often via closed procedures. Little is reported about the experience of these trainees, the quality of their research and career outcomes, or their satisfaction with the research training provided.

The General Medical Council (GMC) quality review of academic training in 2014 provided a detailed insight into the views of trainees undertaking research training. ${ }^{6}$ Although most trainees had a positive view of their research training, there was no assessment of whether funding source impacted on this. The GMC review identified concerns from both trainees and their supervisors regarding trainees' potential loss of clinical skills and the processes for supporting their return to clinical practice following a period of research training. It did not investigate whether trainees perceived their clinical practice benefited from the research experience.

To build on the previous research, we aimed to systematically survey all trainees within the Health Education England West Midlands clinical training programme who undertook a period of research training. We aimed to compare the experience and outcomes of trainees funded by the NHS with those funded through CRTFs using an online questionnaire. In addition, we aimed to investigate the trainees' satisfaction with the research and how the research training impacted on their return to clinical training.

\section{METHODS}

\section{Survey}

An online questionnaire was sent to West Midland's trainees who had undertaken a period of research training and subsequently returned to clinical training between 2009 and 2015. The questionnaire was administered from January to May 2016. Four reminders were sent to encourage participation. Trainees were identified from records held by the Local Education and Training Board, which were collected prospectively when trainees applied for approval to take time 'Out of Programme' for research (OOPR). All participants provided informed consent prior to completing the survey.

\section{Survey questions}

The survey questions covered three areas: trainee characteristics, including funding source, experience during research training and progress following completion of research training (see online supplementary appendix 1 for full questionnaire). The aim of the survey was to gather mainly quantitative data but also allowed participants to clarify or qualify their responses by the addition of free-text answers. The questionnaire was designed to allow comparison between participants who self-identified as being in receipt of NHS funding for their research training, and those who obtained competitive CRTFs. We did not specifically ask trainees where funding came from when defined as NHS funded. Those in receipt of CRTFs were asked to identify whether their funding was from MRC, Cancer Research UK (CRUK), NIHR, Wellcome Trust or other charities. We also aimed to assess the overall value of the research experience. This included satisfaction with the outcome of their research and the support they received from their academic supervisor; we did not ask whether the academic supervisor was employed by a Higher Education Institute or the NHS, although many supervisors work across both sectors. Participants were also asked to quantify the influence they perceived their research training has had on their career or future career choice and if they felt there had been any impact on the quality of the clinical care they provided on return to clinical practice. Finally, participants were asked about their progress following research experience on return to clinical training (see online supplementary appendix 1 for full questionnaire). The survey was piloted in five trainees, for facility of completion and excluding ambiguous questions, prior to contacting the wider trainee population.

\section{Data analysis}

The questions and measurement scales used in the questionnaire were largely adopted from previous studies that also measured career choice ${ }^{5}$ and participant satisfaction (National Student Survey, 2016), in order to provide content reliability and validity. The level of internal consistency of the items in the satisfaction scales was acceptable at 0.77 as measured by Cronbach's alpha test. For the purposes of this study participants who identified 
Table 1 Responder profile

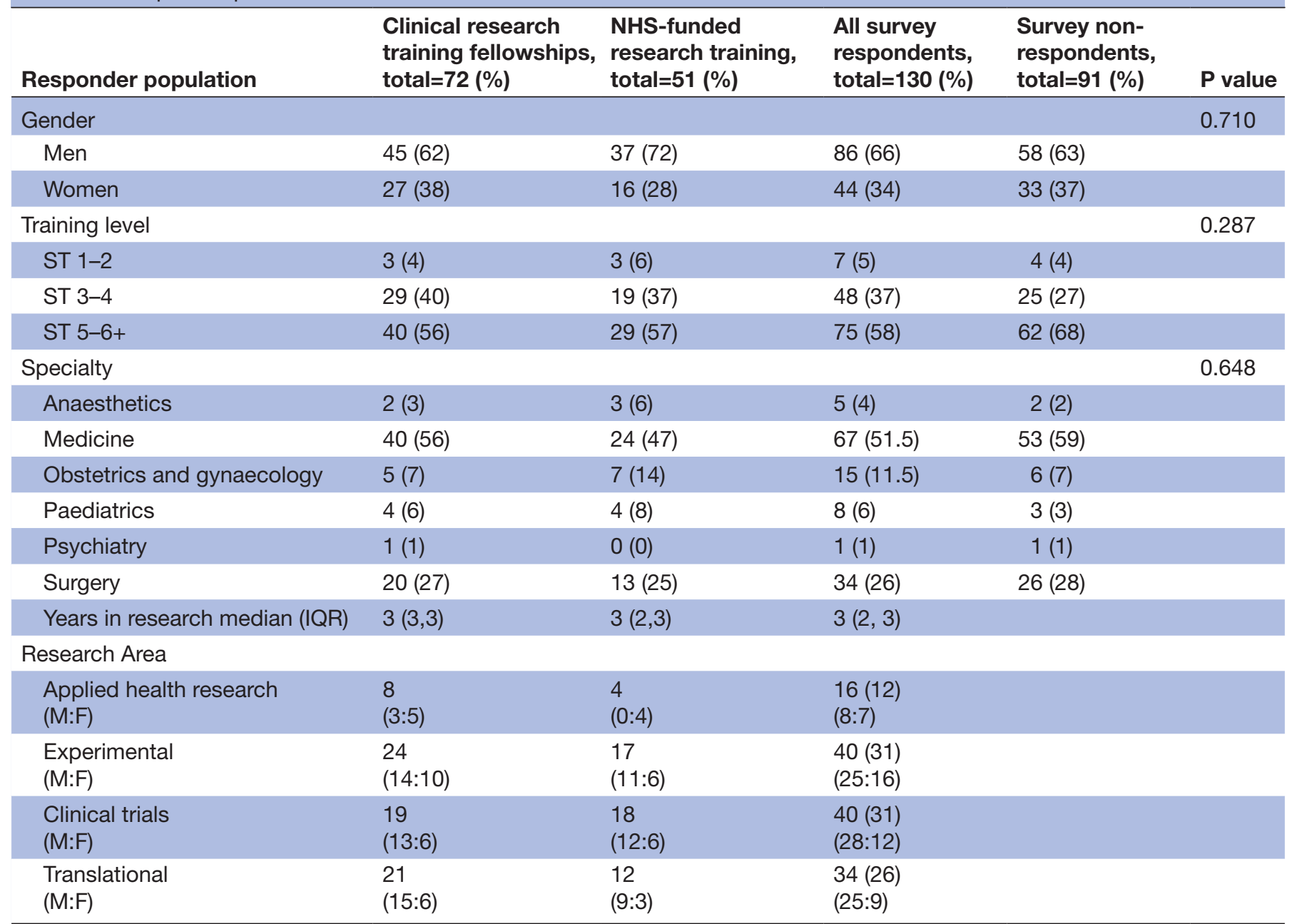

Comparisons are made between the whole population who responded and did not respond.

F, female; M, male; NHS, National Health Service; ST, specialty training level.

NHS funding but then progressed to CRTFs were considered to be NHS funded. Self-funding participants were excluded from the analysis of funding source.

Categorical variables are shown as number (percentage). Differences between groups were analysed by Pearson's $\chi^{2}$ test. Analysis of free-text responses was performed using conventional content analysis ${ }^{7}$ to identify themes and the number of participants mentioning each recurrent theme was counted.

\section{RESULTS}

\section{Survey response rates and characteristics of participants}

Two hundred and twenty-two participants completed OOPR training between 2009 and 2015. The overall response rate to the survey was 138/222 (62\%), with eight responses removed due to incomplete data, which reduced the final response rate to $130(58.8 \%)$.

The genders, training stages and specialties of the 130 participants who responded were comparable to the overall West Midlands trainee population who undertook research (table 1). Participants were enrolled in a broad range of secondary care specialties with the majority in hospital medicine $(51 \%)$ or surgery $(26 \%)$. One hundred and twenty-three $(94 \%)$ were in specialty training. Ninety-two $(71 \%)$ participants undertook a period of research training of 3 years or more. Participants were asked to describe the research they undertook with $52 \%$ having some laboratory experience (experimental/translational research) and 30\% were involved in running clinical trials. It was notable that although there were fewer women than men undertaking research there were no differences in the gender distribution across the research areas (table 1$)$ defined by the participants $(\mathrm{P}=0.443)$.

\section{Funding source}

Seventy-two participants $(55 \%)$ held competitively funded CRTFs (11 from the Wellcome Trust, 12 from MRC, 11 NIHR and 38 other charities) and 51 participants (39\%) reported the NHS as a source of funding, three of whom subsequently obtained CRTFs (one MRC and two other). Seven participants identified as self-funding. There was no difference in the funding sources between men and women $(\mathrm{P}=0.395)$ or associated with specialty $(\mathrm{P}=0.91)$. 


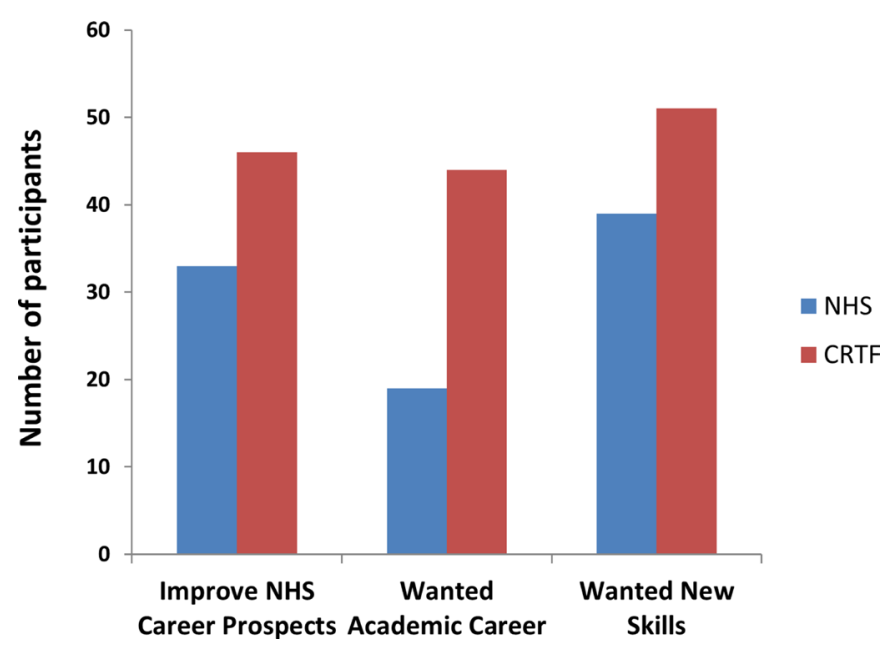

Figure 1 Reported motivation for undertaking research training by NHS-funded and CRTF participants. CRTF, clinical research training fellowship; NHS, National Health Service.

The majority of participants $(58 \%)$ undertook research in the later years of clinical training (ST 5-6 or above); there was no association between stage of training and funding source $(\mathrm{P}=0.89)$. There was no difference in duration of research $(\mathrm{P}=0.76)$ or area of research $(\mathrm{P}=0.69)$ when comparing funding source.

\section{Motivation}

Participants were asked about their motivation to undertake the research training and were provided with three options to select; improving career prospects, developing new skills and wishing to pursue an academic career. Responders were able to select all responses that were applicable, or add a free-text response. The majority of participants $(68 \%)$ cited more than one reason for undertaking research training. The most common motivating factors for participants to undertake research training were a desire to develop new skills and improve NHS career prospects (figure 1). Of those who selected improving NHS career prospects, $40 \%$ also reported that they wished to pursue an academic career. Participants funded through CRTFs were more likely to report wanting an academic career as motivation for undertaking research than those funded by the NHS (44/72 CRTFs compared with 20/51 NHS, $\mathrm{P}=0.017)$. Thirteen participants reported additional reasons which include three wishing to experience an academic career (two CRTF and one NHS), two to provide better care (one CRTF and one NHS), two to delay Certificate of Completion of Training (both CRTF), one advised by mentors (NHS), three to understand mechanism of disease better (two CRTF and one NHS), one as it provided flexibility to spend more time with a young family (NHS) and one to provide the opportunity to work overseas (CRTF).

\section{Research training success}

One hundred and seven $(82 \%)$ participants were awarded a higher degree following their research training (66 $\mathrm{PhD}, 31 \mathrm{MD}$ and 10 master's level qualification). At the time of the questionnaire 23 participants had not been awarded a higher degree but 8 planned to submit a thesis in the future and 3 were resubmitting after corrections had been addressed. Of the others, two NHS-funded participants reported that they had not registered with a university for a higher degree, two did not have sufficient funding to complete their research (one NHS and one CRTF) and six participants did not provide an explanation. Participants with a CRTF were more likely to have been awarded a degree than those with NHS funding (66/72 CRTFs and 37/51 NHS, $\mathrm{P}=0.005$ ) (table 2). There was no difference in the type of degree undertaken based on funding (45/66 PhDs CRTF compared with 20/37 PhDs NHS, $\mathrm{P}=0.259$ ) and no difference between those awarded a degree and their specialty $(\mathrm{P}=0.76)$ or stage of training $(\mathrm{P}=0.91)$.

One hundred and seven participants (82\%) were satisfied with their research supervisor. Participants who were not awarded a higher degree were more likely to report dissatisfaction or were neutral about the support received from their research supervisor although this did not reach statistical significance (7/23 (30\%) vs $16 / 107(15 \%), \mathrm{P}=0.078)$. Only four participants provided additional information on why they were dissatisfied, two identified supervisor's lack of competence in the area of research, and two identified supervisor absence or supervisor's lack of time to supervise. There was no difference with supervisor satisfaction

Table 2 Analysis by funding support

\begin{tabular}{|c|c|c|c|c|}
\hline & $\begin{array}{l}\text { CRTF } \\
\text { funders }(n=72)(\%)\end{array}$ & $\begin{array}{l}\text { NHS } \\
(n=51)(\%)\end{array}$ & $\begin{array}{l}\text { Self-funded } \\
(n=7)(\%)\end{array}$ & P value \\
\hline Degree awarded & $66(92)$ & $37(73)$ & $4(57)$ & 0.005 \\
\hline Satisfaction with supervisor support & $59(82)$ & $42(82)$ & $6(86)$ & 0.95 \\
\hline Participated in research on return to clinical work & $53(73)$ & $30(59)$ & $5(71)$ & 0.085 \\
\hline Struggle on return to work & $21(30)$ & $12(24)$ & $2(29)$ & 0.48 \\
\hline
\end{tabular}

CRTF, clinical research training fellowship; NHS, National Health Service. 
reported by participants when comparing CRTF and NHS funding (table 2).

Participants were asked about publication record (0, 1-2, 3-4 or $\geq 5$ publications), only two participants reported no publications, both were recipients of CRTFs; $77 \%$ of participants reported three or more publications with no difference between those funded by CRTF or NHS (table 2).

Ninety-five per cent of the participants reported that they would recommend a period of research training to colleagues (table 2).

\section{Impact of research training on career}

Participants were asked about the impact of the research training on their career choice; $92 \%$ of participants felt that it had an impact, with 69 of 130 participants describing the impact as very or having extreme impact. Participants who were awarded a PhD were more likely to wish to pursue a formal clinical academic role whereas participants undertaking an MD were more likely to wish to pursue an NHS career with research content $(30 / 66$ PhD compared with $7 / 31$ MD who desired a formal clinical academic career, $\mathrm{P}=0.031$ ).

Eighty-five $(69 \%)$ participants have continued to participate in research activity following completion of their research; of whom 24 (28\%) progressed into a clinical lecturer post following completion of their research training (8/51 NHS and 16/72 CRTF, $\mathrm{P}=0.37)$. There was no difference between funding sources and continued participation in research (table 2). At the time of the questionnaire 57 participants had finished clinical training and were employed at consultant level, 9 had progressed to further academic positions ( 3 of 25 NHS funded and 6 of 32 CRTF, $\mathrm{P}=0.49$ ) and 26 participants in clinical posts had research included as part of their consultant programmed activities (12/22 NHS and 14/26 CRTF, $\mathrm{P}=0.96$ ).
Table 3 Number of participants continuing in clinical activity during research training

\begin{tabular}{lclll}
\hline & None & $\begin{array}{l}\text { Clinic } \\
\text { only }\end{array}$ & $\begin{array}{l}\text { On-call } \\
\text { only }\end{array}$ & $\begin{array}{l}\text { Both on-call and } \\
\text { clinic }\end{array}$ \\
\hline PhD & 14 & 24 & 9 & 19 \\
MD & 2 & 10 & 7 & 12 \\
MSc & 4 & 4 & 0 & 2 \\
No degree & 2 & 2 & 9 & 10 \\
\hline
\end{tabular}

Participants were asked whether their research training improved their provision of clinical care. They were then provided with six options to describe the impact the research experience may have had with the opportunity to provide their own free-text answer. Participants were allowed to register more than one answer (figure 2). One hundred and six (82\%) participants felt that their OOPR experience had improved the quality of clinical care they provide. The most frequently stated areas of improvement included better understanding of evidence-based medicine and improved critical assessment of complex problems.

\section{Maintenance of clinical skills and return to the clinical workplace}

One hundred and eight (83\%) reported that they continued to undertake some clinical work during their research training and all of these individuals felt that continuing with clinical work helped them to some extent with their return to clinical practice. The type of clinical work undertaken was on-call duties only $(\mathrm{n}=25(24 \%))$, clinics only $(n=40(37 \%))$ or both $(n=43(48 \%))$. There were no differences between funding source in clinical commitment (NHS 45/51 participants and CRTF 57/72, $\mathrm{P}=0.19$ ). There was no association between continuing

\section{Improved trainee supervision \\ Improved communication skills \\ Improved time management}

Improved team working

Improved critical assessment of complex problems

\author{
Understanding of evidence-based medicine
}

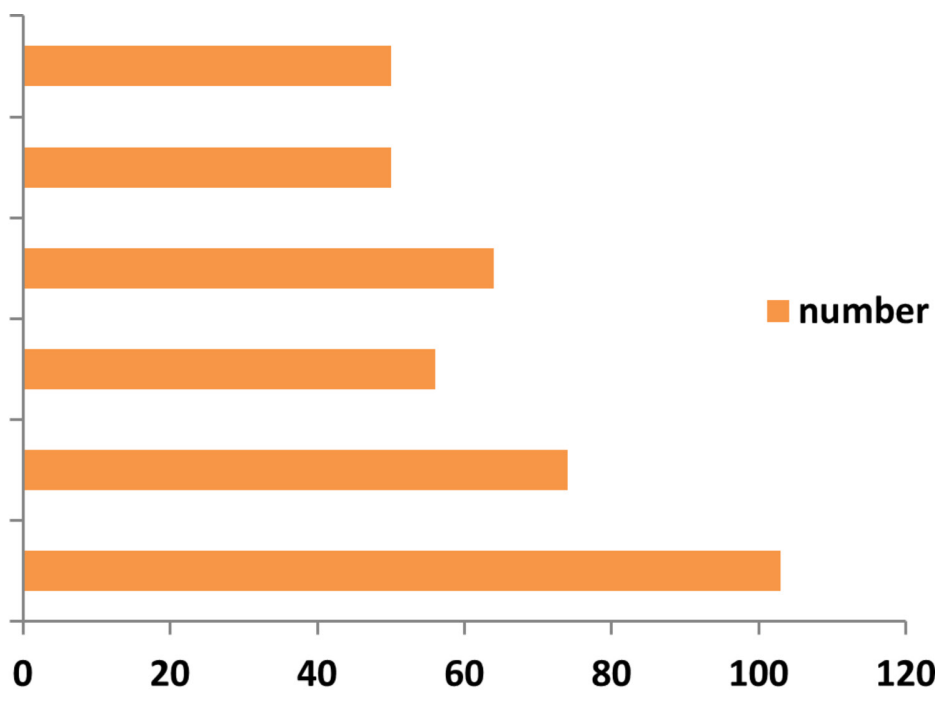

Number of participants

Figure 2 Aspects of clinical care that participants felt had improved following out of programme for research (OOPR). 
clinical work and being awarded a degree $(\mathrm{P}=0.246)$ (table 3).

Fifty-nine $(45 \%)$ participants reported feeling somewhat or significantly isolated from clinical peers while undertaking their research. Feelings of isolation were less common in those who continued clinical work compared with those who did not, although this was not statistically significant $(42 \%$ vs $61 \%, \mathrm{P}=0.059)$.

Thirty-five participants (27\%) reported that they struggled following return to clinical work after their research training, with a reduction in clinical skills being the biggest concern (26/35 participants), followed by concerns about reintegration into the clinical team/environment (17/35 participants). Other themes identified by participants included a lack of clinical supervision (two participants) and difficulty balancing the workload of completing their thesis submission and clinical training (three participants). Participants who undertook clinical work during research training were significantly less likely to struggle on returning to work than those who did not undertake clinical work (23/108 continued clinical work vs $12 / 22$ no clinical work, $\mathrm{P}=0.001$ ).

\section{DISCUSSION}

Although it is well established that CRTFs provided by the MRC and charities are important in the capacity development of clinical academics ${ }^{3-5}$ the role of the NHS in this regard has not been previously investigated. One-third of participants in the West Midlands were funded through the NHS to undertake formal research training. The research experience of participants supported by funding administered by the NHS is positive and has a similar impact on future careers, in the short term, to those supported by CRTFs. Overall, $28 \%$ of participants progressed to a clinical lecturer role, of whom one-third had received funding from the NHS. Participants who were recipients of CRTFs had higher rates of degree conferment (90\%) than those funded from the NHS $(68 \%)$. Despite this there was no difference in the proportions of NHS-funded and CRTF-funded participants continuing to participate in research following return to clinical work and they had similar success in achieving three or more publications. It is recognised that completion of a higher degree may not be a reliable surrogate marker of future engagement in research and prospective studies investigating the outcome of research training based on funding source is required to better understand the real impact on long-term research engagement by clinicians. This is the first study to provide evidence that research training for doctors funded through the NHS is important in building a research active clinical workforce.

Trainee perception of the impact of research training on their clinical abilities has not previously been reported. Participants reported that they felt the experience enhanced their clinical performance and 95\% would recommend a period of research training. This perception is supported by recent findings that scholarly activity, as measured by publication record, is associated with better clinical performance. ${ }^{8}$ It has been suggested that research and clinical practice both require the skills of time management, efficiency, diligence and effective teamwork. ${ }^{9}$ This is supported by our trainee perceptions that these skills are enhanced by research training. Evidence also suggests that research active NHS trusts have lower mortality rates for acute admissions ${ }^{10}$ and research engagement has a beneficial impact on healthcare performance. ${ }^{11}$ The skills identified as being enhanced by our participants may contribute to this improved performance. The NHS funds over one-third of research training opportunities for doctors within the West Midlands and this study provides support for the continuation of that funding for development of a research active future medical workforce.

\section{Strengths and limitations}

Most previous studies have looked at CRTF funding schemes. ${ }^{34}$ The 2015 MRC report attempted to look at a wider range of schemes in partnership with NIHR, CRUK, British Heart Foundation and the Wellcome Trust and to look at outcomes from those who failed to get funding through these schemes. ${ }^{5}$ However, the response rate to the study was poor with only $36 \%$ of invitees responding, of whom $72 \%$ of the responders had been awarded a fellowship. It is difficult to understand outcomes of those who did not receive a CRTF from this MRC led study. Data in this study on participants who benefited from NHS-administered funding is particularly novel. The present study benefited from a systematic approach, inviting all participants who had completed OOPR within the West Midlands to participate in the study. Although this survey is limited by its questionnaire methodology, response rates were comparable to other studies addressing career outcomes for academic trainees ${ }^{12} 13$ and represented the wider community undertaking research training in the West Midlands. Although demographics were similar between responding and non-responding trainees it is unknown whether funding source or other outcomes differed in those who failed to complete the survey. The study may also have a geographical bias as the study was undertaken in a single geographical training area, the West Midlands which has a slightly lower percentage of licensed female doctors (41\%) and higher proportion of licensed doctors who are non-UK graduates relative to the UK average. ${ }^{14}$ As the study was retrospective in nature, it is possible that responses were affected by recall bias when trainees completed the survey.

\section{Implications}

The smaller proportion of NHS-funded participants having a higher degree conferred is disappointing. This may reflect differences in the qualities of successful applicants for NHS and CRTF funding or the rigorous peer review and interview process that is required before award of CRTFs. CRTFs are highly competitive with many schemes reporting only a 10\%-20\% success rate. A recent 
study reported that medical trainees enrolled on $\mathrm{PhD}$ programmes at two research intensive universities had high levels of previous research experience ${ }^{12}$; we did not examine previous research experience in our study. We did not identify any association between continuing clinical work and being awarded a higher degree. Using clinic or on-call commitment only or combined clinic and on-call commitment as a surrogate measure of work load there was no association between different clinical workloads and failure to be awarded a higher degree. Data collected in this study did not allow us to identify the reasons for the lower rate of degree awards to NHS research fellows, although there was a trend for trainees who were not awarded a higher degree to report dissatisfaction with their research supervisor. Consideration should be given by those who approve OOPR training to ensure that research projects are appropriately peer reviewed and supervised prior to approval if the trainee is not funded via a CRTF.

Participants were very positive about their research training experience, with 95\% recommending such experience to colleagues. However, returning to the workplace following a period of OOPR was identified as an area where improvements could be implemented. Despite the high number of participants reporting that OOPR had improved the quality of the clinical care they provide, a significant number also responded that they struggled when returning to the workplace. Those participants who maintained clinical contact during research training were less likely to struggle on return to work. It is recognised that clinical skills decline with time away from practice ${ }^{15}$ and the GMC, in their recent quality review of academic training, note a requirement for clear return to clinical practice processes for those returning to clinical training from research. ${ }^{6}$ It is essential that those overseeing clinical training develop return to work packages that are tailored to the needs of participants. These should be developed, in accordance with the Joint Royal Colleges of Physicians Training Board and Academy of Medical Royal Colleges guidance, towards the end of research training with a focus on keeping in touch activities, agreement on learning and training needs and a record of reintroduction to clinical activities overseen by strong supervisory activity that ensures competence. ${ }^{16}$ This needs to be communicated to trainees. Research supervisors must also have the time and competencies to support participants, as $70 \%$ of participants not awarded a higher degree expressed dissatisfaction or neutral satisfaction with their research supervision. Due to the nature of the survey it is difficult to comment more on this issue.

\section{Conclusion and further research}

The results of this study provide strong evidence that research training is a valuable entity to almost all participants who undertake this experience, with $95 \%$ of participants stating they would recommend research training to other doctors. Research funded through the NHS provides an important source of capacity development for clinical academics and this report supports continuation of that funding stream. Further research is required to understand the reasons behind lower degree conferment for those funded by the NHS and the support required to improve this.

Contributors $\mathrm{CM}$ and $\mathrm{LH}$ developed the questionnaire. CM collected the data. All authors (CM, MDM, RS, LH) conceived the data analysis plan and later made substantive contributions to the interpretation of the findings and the writing of this article. CM and LH conducted the quantitative data analysis and reporting. $\mathrm{CM}, \mathrm{MDM}, \mathrm{RS}$ and LH wrote the first and subsequent drafts. All authors (CM, MDM, RS, LH) critically reviewed and edited drafts and approved the final version of the manuscript. They also had full access to all of the data (including statistical reports and tables) in the study and can take responsibility for the integrity of the data and the accuracy of the data analysis. The study guarantor is $\mathrm{LH}$.

Funding This research received no specific grant from any funding agency in the public, commercial or not-for-profit sectors.

Competing interests $\mathrm{CM}, \mathrm{RS}$ and $\mathrm{LH}$ declare that their salary is, in part, paid for by Health Education England in the West Midlands.

Patient consent Not required.

Ethics approval The study protocol was approved by the University of Worcester Research Ethics Committee.

Provenance and peer review Not commissioned; externally peer reviewed. Data sharing statement No additional data are available.

Open Access This is an Open Access article distributed in accordance with the Creative Commons Attribution Non Commercial (CC BY-NC 4.0) license, which permits others to distribute, remix, adapt, build upon this work non-commercially, and license their derivative works on different terms, provided the original work is properly cited and the use is non-commercial. See: http://creativecommons.org/ licenses/by-nc/4.0/

C) Article author(s) (or their employer(s) unless otherwise stated in the text of the article) 2018. All rights reserved. No commercial use is permitted unless otherwise expressly granted.

\section{REFERENCES}

1. Ley TJ, Rosenberg LE. The physician-scientist career pipeline in 2005: build it, and they will come. JAMA 2005;294:1343-51.

2. Weber GM. Identifying translational science within the triangle of biomedicine. J Trans/ Med 2013;11:126.

3. Stewart PM, Bryan S, Dukes P, et al. What happens to clinical training fellows? A retrospective study of the 20 years outcome of a Medical Research Council UK cohort. BMJ Open 2012;2:e001792.

4. Shalhoub J, Cromwell D, Coomer M, et al. The impact of the royal college of surgeons of england research fellowship scheme. Ann $R$ Coll Surg Engl 2016;98:431-5.

5. IFF Research. A cross-funder review of early-career clinical academics: enablers and barriers to progression, 2015. A Review led by the Medical Research Council in collaboration with the Academy of Medical Sciences, British Heart Foundation, Cancer Research UK, National Institute for Health Research and Wellcome Trust.

6. General Medical Council. Quality assurance report for academic training. 2014. http://www.gmc-uk.org/Academic_training_report_ and_responses_Final.pdf_58315393.pdf

7. Hsieh HF, Shannon SE. Three approaches to qualitative content analysis. Qual Health Res 2005;15:1277-88.

8. Seaburg LA, Wang AT, West CP, et al. Associations between resident physicians' publications and clinical performance during residency training. BMC Med Educ 2016;16:22.

9. Calhoun $\mathrm{KH}$, Bailey BJ. Thriving in academic medicine. Otolaryngol Head Neck Surg 1997;117:575-9.

10. Ozdemir BA, Karthikesalingam A, Sinha S, et al. Research activity and the association with mortality. PLoS One 2015;10:e0118253.

11. Hanney S, Boaz A, Jones T, et al. Engagement in research: an innovative three-stage review of the benefits for health-care performance. Southampton: National Institute for Health Research, 2013.

12. Lopes J, Ranieri V, Lambert T, et al. The clinical academic workforce of the future: a cross-sectional study of factors influencing career 
decision-making among clinical $\mathrm{PhD}$ students at two researchintensive UK universities. BMJ Open 2017;7:e016823.

13. Blencowe NS, Glasbey JC, McElnay PJ, et al. Integrated surgical academic training in the UK: a cross-sectional survey. Postgrad Med J 2017;93:581-6.

14. General Medical Council. Our data on doctors working in the UK GMC. 2015. http://www.gmc-uk.org/Chapter_1_SOMEP_2015.pdf_ 63501394.pdf
15. Skills fade: a review of the evidence that clinical and professional skills fade during time out of practice, and of how skills fade may be measured or remediated. 2014. http://www.gmc-uk.org/Skills_fade literature review final Report.pdf 60956354.pdf

16. Colleges AoMR. Return to work guidance, revision 2017. 2017. http://www.aomrc.org.uk/wp-content/uploads/2017/06/Return_to_ Practice_guidance_2017_Revison_0617-2.pdf 